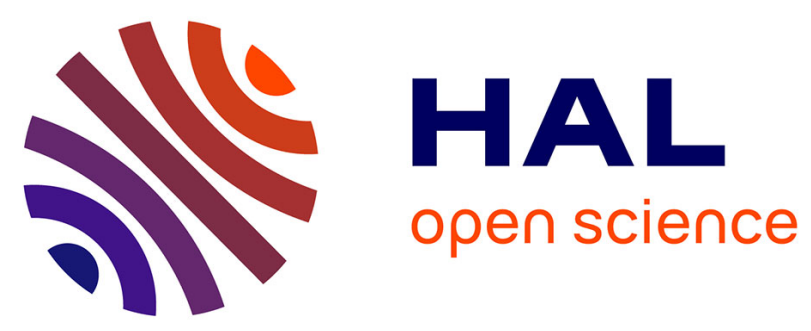

\title{
Low temperature homoepitaxy of GaN by LP-MOVPE using Dimethylhydrazine and Nitrogen
}

\author{
Corinne Sartel, Simon Gautier, S. Ould Saad Hamady, N. Maloufi, Jérôme \\ Martin, Andrei Sirenko, Abdallah Ougazzaden
}

\section{- To cite this version:}

Corinne Sartel, Simon Gautier, S. Ould Saad Hamady, N. Maloufi, Jérôme Martin, et al.. Low temperature homoepitaxy of GaN by LP-MOVPE using Dimethylhydrazine and Nitrogen. Superlattices and Microstructures, 2006, 40, pp.476-482. 10.1016/j.spmi.2006.09.026 . hal-00181631

\section{HAL Id: hal-00181631 \\ https://hal.science/hal-00181631}

Submitted on 1 Dec 2021

HAL is a multi-disciplinary open access archive for the deposit and dissemination of scientific research documents, whether they are published or not. The documents may come from teaching and research institutions in France or abroad, or from public or private research centers.
L'archive ouverte pluridisciplinaire HAL, est destinée au dépôt et à la diffusion de documents scientifiques de niveau recherche, publiés ou non, émanant des établissements d'enseignement et de recherche français ou étrangers, des laboratoires publics ou privés.

\section{(ㄷ)(1) $\$$}

Distributed under a Creative Commons Attribution - NonCommerciall 4.0 International 


\title{
Low temperature homoepitaxy of GaN by LP-MOVPE using Dimethylhydrazine and nitrogen
}

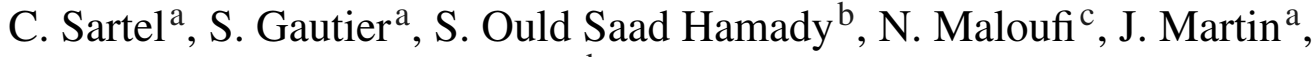 \\ A. Sirenko ${ }^{\text {d }}$ A. Ougazzaden ${ }^{\mathrm{e}, *}$ \\ ${ }^{a}$ Laboratoire Matériaux Optiques, Photonique et Systèmes - UMR CNRS 7132, Université de Metz and SUPELEC, \\ 2 rue E. Belin 57070 Metz, France \\ ${ }^{\mathrm{b}}$ LMOPS-UMR CNRS 7132 - UMI 2958 Georgia Tech-CNRS, France \\ ${ }^{\mathrm{c}}$ Laboratoire d'Etude des Textures et Application aux Matériaux UMR CNRS 7078 Ile du Saulcy 57045 METZ cedex 1, \\ France \\ ${ }^{\mathrm{d}}$ Department of Physics, New Jersey Institute of Technology, Newark, NJ 07102, United States \\ ${ }^{\mathrm{e}}$ Georgia Institute of Technology/GTL 2-3 rue Marconi 57070 Metz - UMI 2958 Georgia Tech-CNRS, France
}

Thin films of $\mathrm{GaN}$ with the $\mathrm{V} / \mathrm{III} \approx 10$ ratio were grown by low-pressure metal organic vapour phase epitaxy (LP-MOVPE) using $\mathrm{N}_{2}$ and Dimethylhydrazine (DMHy) as a carrier gas and nitrogen precursor, respectively. For the growth temperatures in the range from 550 to $690{ }^{\circ} \mathrm{C}$ the $\mathrm{GaN}$ layers exhibited good surface morphology. In the temperature range from approximately 550 to $610^{\circ} \mathrm{C}$, the growth rate increases with increasing temperature, characteristic of the process limited by surface kinetics with the activation energy of approximately $36 \mathrm{kcal} / \mathrm{mol}$. For the temperatures between 620 and $690{ }^{\circ} \mathrm{C}$, the growth rate was nearly independent of temperature, which is indicative of a mass transport limited growth. The activation energy was about $4.6 \mathrm{kcal} / \mathrm{mol}$. Micro Raman spectroscopy revealed a significant relaxation of the selection rules for the scattering by the optical phonons in the films grown at lower temperatures. Variation of the intensity ratio for $E_{2}{ }^{H}$ and $E_{1}$ phonon modes has been attributed to the changes in the structural quality of the films grown at different temperatures.

Keywords: LP-MOVPE; GaN; DMHy; Micro-Raman spectroscopy

\footnotetext{
* Corresponding author. Tel.: +3303872039 23; fax: +330387203940.

E-mail address: aougazza@georgiatech-metz.fr (A. Ougazzaden).
} 


\section{Introduction}

Wide Band Gap semiconductors, such as GaN and related alloys (GaAlN, InAlN, InGaN), exhibit many attractive electronic and optical properties which make them ideal candidates for light emitting diodes (LEDs) and laser diodes operating throughout ultra violet to green visible spectral range as well as for high power and high frequency applications. One of the limiting aspects of GaN-based materials is their relatively poor crystal quality due to the necessity of heteroepitaxy. In some cases $\mathrm{GaN}$ buffer layer grown at low temperature on sapphire, silicon carbide or zinc oxide substrates is a necessary pathway process in order to improve the structural quality of these heterostructures. Ammonia $\left(\mathrm{NH}_{3}\right)$ is a conventional atomic nitrogen precursor for high temperature metal organic vapour phase epitaxy (MOVPE) growth of GaN-based materials. Unfortunately, this gas is not convenient for low temperature growth because of its low dissociation efficiency even at high temperature (only $15 \%$ decomposes at $950{ }^{\circ} \mathrm{C}$ ) [1], which is attributed to the strong boundary energy $\mathrm{N}-\mathrm{H}(104 \mathrm{kcal} / \mathrm{mol})$. As a result, alternative precursors have been studied as hydrazine $\left(\mathrm{N}_{2} \mathrm{H}_{4}\right)$ [2], Dimethylhydrazine $\left(\left(\mathrm{CH}_{3}\right)_{2} \mathrm{NNH}_{2}\right)$ [3-7], and tertiabutylhydrazine (tbu- $\left.\mathrm{NH}_{2}\right)$ [8]. In addition to low temperature decomposition the nitrogen precursor has to fulfill more practical requirements such as low toxicity, high purity, liquid at room temperature and high vapour pressure.

In this work, we have chosen the DMHy as a nitrogen source, which has been used successfully in the deposition of $\mathrm{GaN}$ on GaAs [7], sapphire [3,5], $\mathrm{Si}(111)$ [4], GaN [6]. Our choice has the following advantages: (a) a relatively high dissociation efficiency at low temperature $\left(50 \%\right.$ decomposes at $420^{\circ} \mathrm{C}$ ) [9], (b) it is more stable than hydrazine, commercially available with high purity, (c) DMHy is liquid at room temperature and, finally, (d) it has high vapour pressure.

In order to explore $\mathrm{GaN}$ growth in wide range of low temperatures $550-690{ }^{\circ} \mathrm{C}$, in this paper we combined DMHy with molecular nitrogen $\left(\mathrm{N}_{2}\right)$, an alternative carrier gas for hydrogen with a low thermal conductivity. In addition, this combination results in a uniform effective V/III ratio over the growth surface.

\section{Experimental}

The growths were carried out by MOVPE in a $T$-shape reactor [10] on $n$-type doped GaN wafers, obtained by deposition of $4 \mu \mathrm{m}$ of GaN layers on sapphire substrates. The growth temperature ranged from 550 to $690{ }^{\circ} \mathrm{C}$ and was measured by a thermocouple placed in the graphite susceptor at few millimetres below the substrate. The growth pressure was 450 Torr, a process gas was nitrogen $\mathrm{N}_{2}$, and the V/III ratio was equal to 11 . TriMethylGallium (TMG) and Dimethylhydrazine (DMHy) were used as sources of gallium and nitrogen respectively. For all the growths the typical thickness layer was $350 \mathrm{~nm}$. The growth rate was estimated in situ by reflectometry using a semiconductor laser operating at a wavelength of $670 \mathrm{~nm}$. The laser beam was focused on the sample surface through a quartz reactor window and the spot size on the sample was $1 \mathrm{~mm}$.

The surface morphology of the layers was examined by a combination of optical microscopy in the Nomarsky mode and atomic force microscopy.

The Raman spectra were measured with a Dilor confocal micro-Raman spectrometer using the excitation laser wavelength of $514.5 \mathrm{~nm}$ and the optical power at about $10 \mathrm{~mW}$ on the sample. The laser beam was focused through a $\times 100$ numerical aperture objective lens. The confocal 


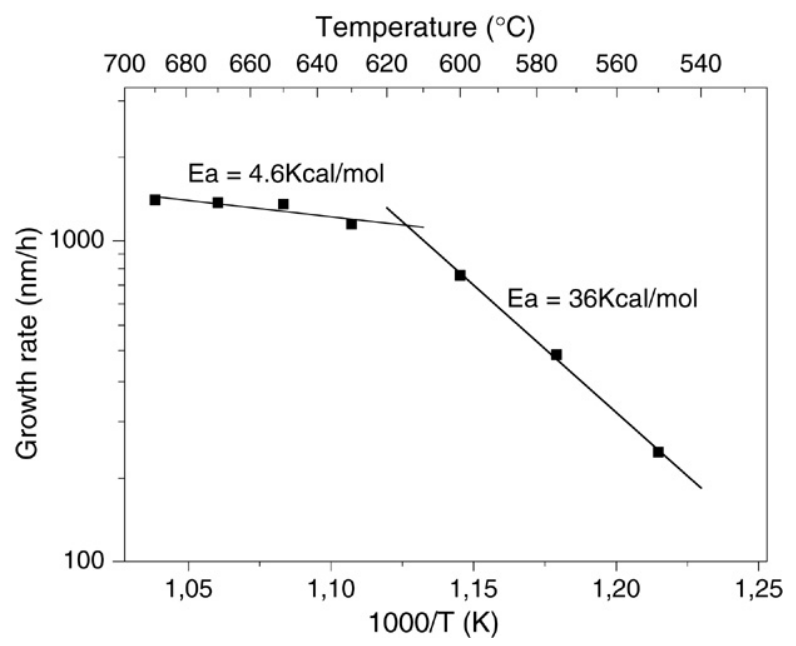

Fig. 1. Growth rate versus $1 / T$ with the Arrhenius line fit.

aperture was fixed to analyze approximately $1 \mu \mathrm{m}^{3}$ of the sampling volume. Polarization of the Raman spectra was analyzed in backscattering geometries.

\section{Results and discussion}

The growth rate was investigated as a function of the growth temperature (Fig. 1). In the temperature range from approximately 550 to $610{ }^{\circ} \mathrm{C}$ the growth rate increases with the temperature, characteristic of the process limited by surface kinetics. In other words, variation of the growth rate was related to the pyrolysis process of TMGa. The data points fit well using Arrhenius plot with the slope corresponding to the activation energy of approximately $36 \mathrm{kcal} / \mathrm{mol}$. This value is slightly higher than the activation energy of $28.5 \mathrm{kcal} / \mathrm{mol}$ under $\mathrm{H}_{2}$ carrier gas reported by Hsu et al. [6]. Between 620 and $690{ }^{\circ} \mathrm{C}$, the growth rate has a much smaller slope corresponding to the activation energy of approximately $4.6 \mathrm{kcal} / \mathrm{mol}$. This growth temperature regime is indicative of a mass transport limited growth. A similar trend in the growth rate vs. temperature was obtained in Ref. [13] with TMGa and $\mathrm{NH}_{3}$ precursors.

Fig. 2 shows several time-dependencies of reflectivity measured for GaN layers grown at different temperatures. We have fixed arbitrarily the point zero in order to facilitate comparison between the reflectance curves. Their exact shape will be discussed below.

Visually, the surface of GaN layers was transparent with brownish colour. Under optical microscope with magnification of up to $\times 1000$, the substrate and all layers show the same surface morphology (Fig. 3). Below we present the materials quality studies using AFM and Raman spectroscopy.

Surface roughness has been characterized by the AFM (Fig. 4). At low temperature growth, a few islands appear on the surface of the layers. Above $600{ }^{\circ} \mathrm{C}$, these islands are more numerous and more regular. The roughness and the $z$-average of the layers increase with the growth temperature (Table 1). The increase of RMS roughness for the layers is correlated to the decreases of reflectance intensity collected during the deposition (see Fig. 2). This phenomenon has been reported in the literature [14,15] and two explanations have been proposed (a) if the amplitude of reflectance oscillations is constant at the beginning of the growth and then decreases after few minutes, this situation indicates that $\mathrm{GaN}$ grows directly in 2D mode from the start. But the 


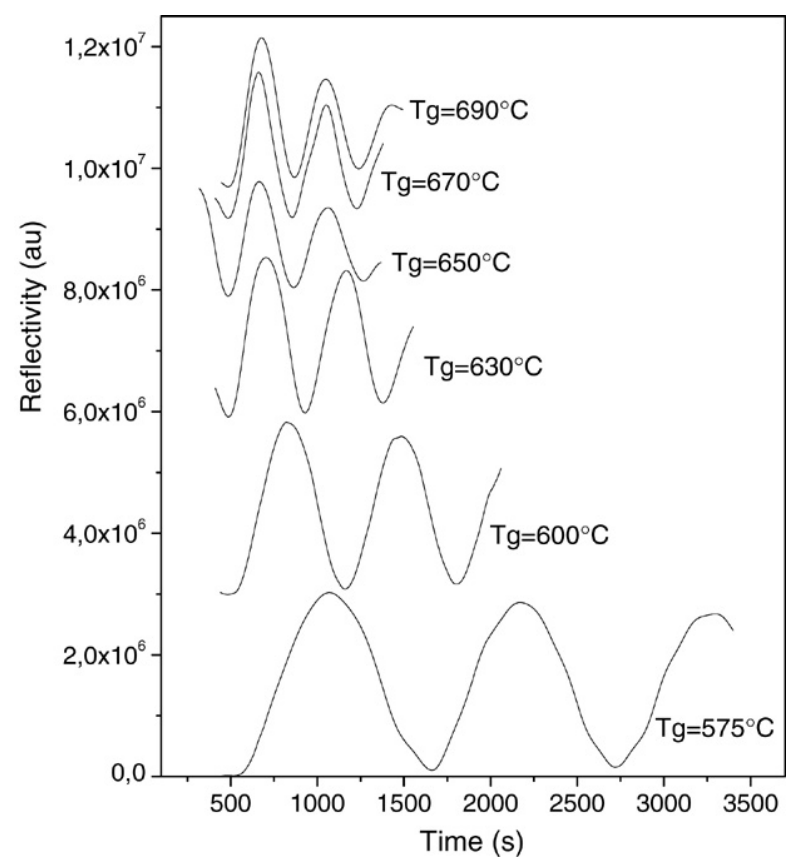

Fig. 2. Reflectance traces of growth versus the growth time.

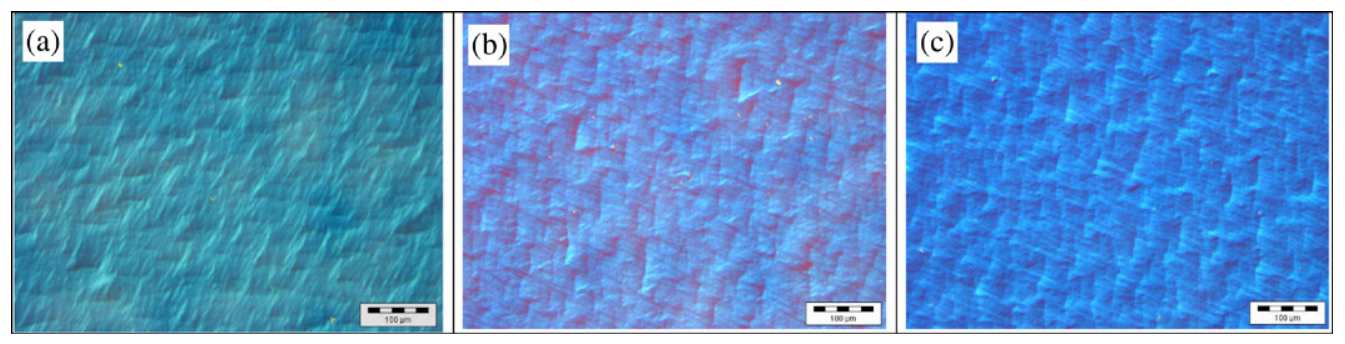

Fig. 3. Optical microscopy images of the $\mathrm{GaN}$ substrate (a), the layers grown at 575 (b) and $650{ }^{\circ} \mathrm{C}$ (c).

surface morphology is deteriorated by hillocks formation [14], (b) if this amplitude decreases right after the start of the growth, that would be a sign of 3D mode growth, and the average roughness increases with the island size. After the coalescence of the islands the reflectance intensity increases [15]. In our case, the amplitude of reflectance decreases just after the start of the deposition. Thus we can argue that the growths begin with formation of the 3D islands.

Raman characterizations: Gallium nitride on sapphire substrate crystallizes in hexagonal (wurtzite; space group $C_{6 \mathrm{v}}^{4}$ ) structure and the group theory predicts eight sets of phonon normal modes at the $\Gamma$ point: $2 A_{1}+2 E_{1}+2 B_{1}+2 E_{2}$. The $A_{1}$ and $E_{1}$ modes are acoustic, while the other six modes, $A_{1}+E_{1}+2 B_{1}$ (silent) $+2 E_{2}$ are optical [11]. Table 2 summarizes the Ramanactive modes for gallium nitride in the backscattering $x(-,-) \bar{x}$ geometries [12]. The $A_{1}$ mode can be observed when the incident and scattered light have parallel polarization (e.g. $x(y, y) \bar{x}$ geometry), while the $E_{1}$ mode is observed only in crossed polarization geometry (e.g. $\left.x(y, z) \bar{x}\right)$. The $E_{2}^{H}$ mode is allowed only in the $x(y, y) \bar{x}$ geometry. 


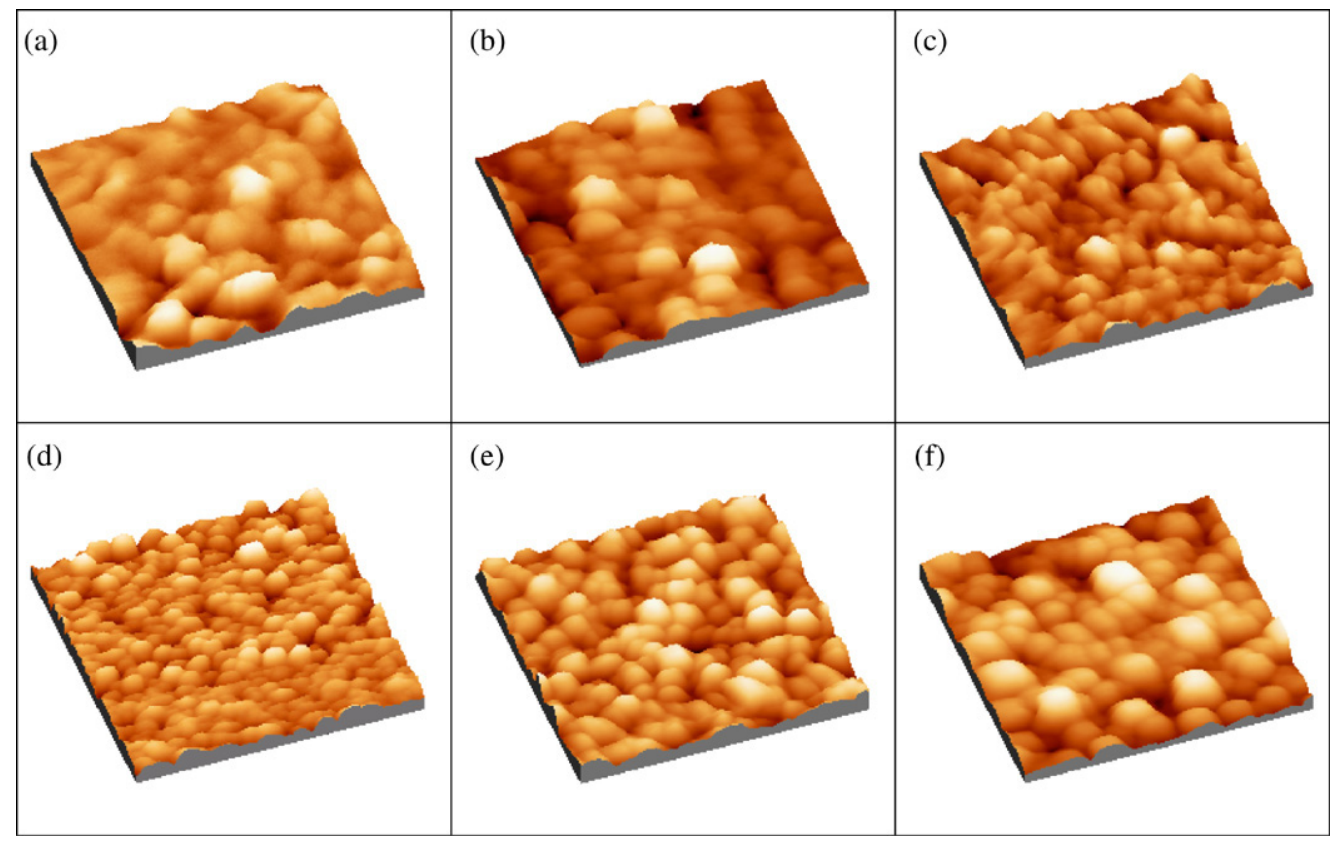

Fig. 4. AFM scans $(1 \mu \mathrm{m} \times 1 \mu \mathrm{m})$ taken on the layers obtained at $550{ }^{\circ} \mathrm{C}(\mathrm{a}), 575^{\circ} \mathrm{C}(\mathrm{b}), 600{ }^{\circ} \mathrm{C}(\mathrm{c}), 650{ }^{\circ} \mathrm{C}(\mathrm{d}), 670{ }^{\circ} \mathrm{C}$ (e) and $690^{\circ} \mathrm{C}(\mathrm{f})$.

Table 1

Evolution of RMS roughness and $z$ average versus the growth temperature

\begin{tabular}{llcc}
\hline Growth temperature $\left({ }^{\circ} \mathrm{C}\right)$ & RMS roughness $(\mathrm{nm})$ & $z_{\text {average }}(\mathrm{nm})$ & $z_{\text {range }}(\mathrm{nm})$ \\
\hline 550 & 1.47 & 5.75 & 11 \\
575 & 2.05 & 6.5 & 15 \\
600 & 2.25 & 7.5 & 17 \\
650 & 2.9 & 11.4 & 24 \\
670 & 4.3 & 14.5 & 28 \\
690 & 4.4 & 13.6 & 28 \\
\hline
\end{tabular}

Table 2

Raman-active modes in the $x(-,-) \underline{x}$ geometries [12]

\begin{tabular}{|c|c|c|}
\hline Geometry & Raman allowed modes & Raman shift $\left(\mathrm{cm}^{-1}\right)$ \\
\hline$x(y, y) \underline{x}$ & $A_{1}(\mathrm{TO}), E_{2}^{H}$ & 533,570 \\
\hline$x(y, z) \underline{x}$ & $E_{1}(\mathrm{TO})$ & 562 \\
\hline$x(z, z) \underline{x}$ & $A_{1}(\mathrm{TO})$ & 533 \\
\hline
\end{tabular}

Fig. 5 shows evolution of the Raman spectra measured in $x(y, z) \bar{x}$ geometry for several samples grown at different temperatures. Raman selection rules allow only $E_{1}$ (TO) modes in this configuration. However, we observed the $E_{2}^{H}$ peak with a relative intensity (with respect to the $E_{1}(\mathrm{TO})$ allowed peak) increasing with decreasing growth temperature. Fig. 6 shows the $E_{2}^{H} / E_{1}(\mathrm{TO})$ intensity ratio as a function of the sample growth temperature. We note also the 


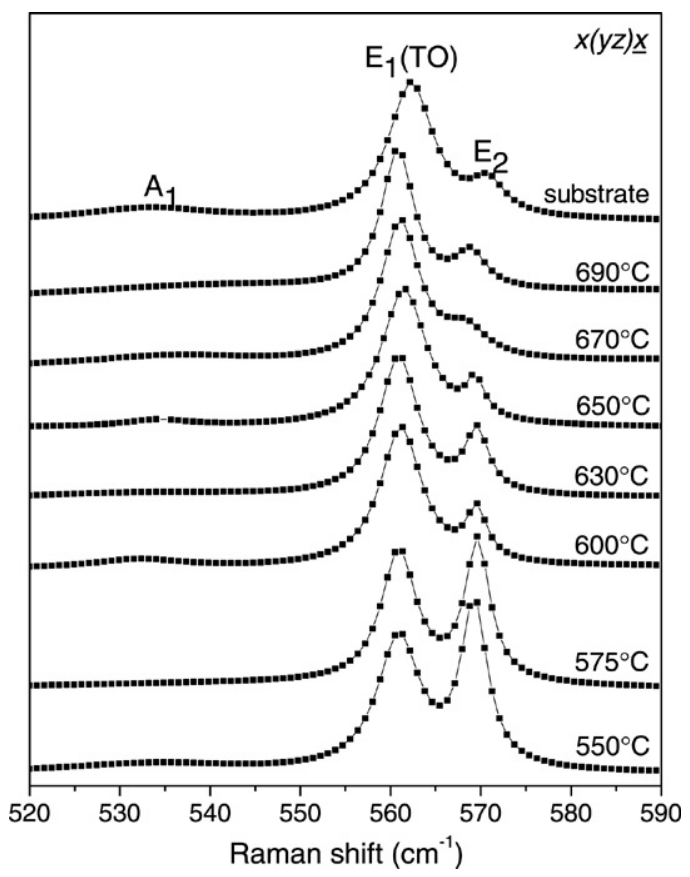

Fig. 5. The growth temperature dependence of Raman spectra in the $x(y, z) \bar{x}$ geometry. All spectra are normalized to the $E_{1}(\mathrm{TO})$ peak intensity.

weak appearance of the $A_{1}$ (TO) mode, which is forbidden in this configuration, with much lower relative intensity than the $E_{2}^{H}$ one. The $E_{2}^{H} / E_{1}(\mathrm{TO})$ peak intensity ratio measured for hightemperature-grown gallium nitride substrate is shown as a reference. The observed relaxation of the Raman selection rules can have two origins: (a) large solid angle of the objective lens of our Raman microscope [12] and (b) disorder in epitaxial layers. For our reference sample high temperature grown $\mathrm{GaN}$ on sapphire - the first reason is dominant for observation of the forbidden modes in $x(y, z) \bar{x}$ geometry with the $E_{2}^{H} / E_{1}$ (TO) peak intensity ratio of about 0.2 . For the low temperature grown GaN samples relaxation of the Raman selection rules is significantly enhanced (Fig. 6) bringing the $E_{2}^{H} / E_{1}$ (TO) peak intensity ratio above 1 . It can only be explained by the crystalline properties of the grown material, namely by the growth temperature-related disorder in the epitaxial layers. Low-temperature samples exhibit the maximum degree of disorder, while for the samples grown at $T \geq 650{ }^{\circ} \mathrm{C} E_{2}^{H} / E_{1}$ (TO) peak intensity ratio became comparable to the reference GaN substrate, thus showing an increase in the layer quality. We can correlate this evolution to the morphology showed in the AFM images (Fig. 4): appearance of islands, probably crystallites at low growth temperature, which coalesce at higher temperature.

\section{Conclusion}

In summary, GaN materials have been grown at low temperature by employing DMHy and $\mathrm{N} 2$ as precursor of nitrogen and carrier gas respectively. Surface roughness at different growth temperatures has been investigated by combining in situ reflectometry and AFM analysis. Micro Raman measurement underlined the enhancement of the structural quality and the degree of disorder as a function of growth temperature. 


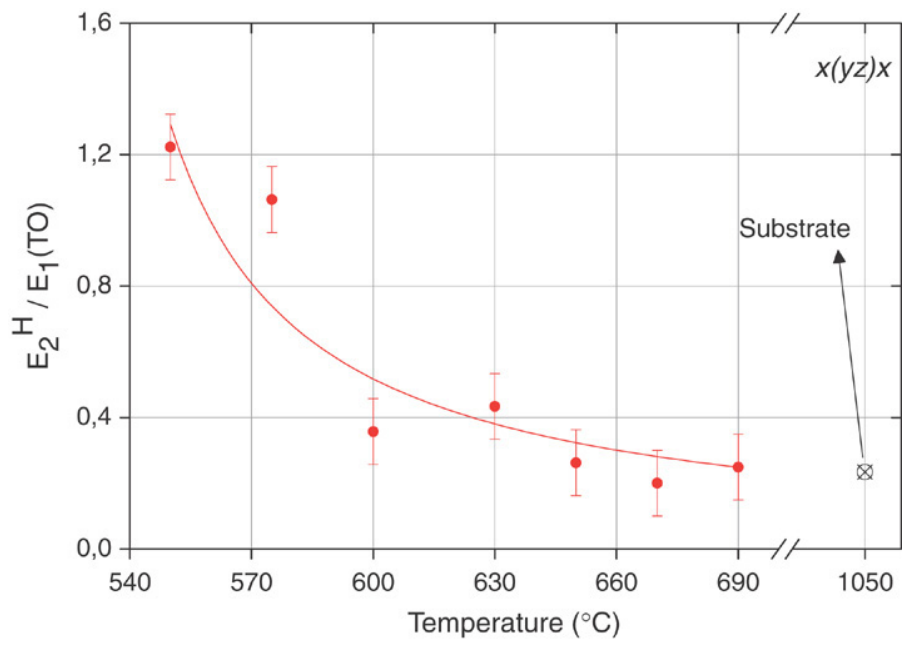

Fig. 6. Evolution of the Raman $E_{2}^{H} / E_{1}$ (TO) peak intensity ratio on the growth temperature. For comparison the ratio for the high temperature growth gallium nitride is shown (for this reference sample, used as substrate, the growth temperature is about $\left.1050^{\circ} \mathrm{C}\right)$.

\section{Acknowledgement}

The author gratefully knowledge Jean Luc Pierrot from University Paul Verlaine Metz for the AFM measurements.

\section{References}

[1] S. Liu, D.A. Stevenson, J. Electrochem. Soc. 125 (1978) 1161.

[2] D.K. Gaskill, N. Bottka, M.C. Lin, J. Cryst. Growth 77 (1986) 418.

[3] H. Sato, H. Takahashi, A. Watanabe, H. Ota, Appl. Phys. Lett. 68 (1996) 3617.

[4] A. Hashimoto, Y. Aiba, T. Motizuki, M. Ohkubo, A. Yamamoto, J. Cryst. Growth 175-176 (1997) 129.

[5] E.D. Bourret-Courchesne, Q. Ye, K.M. Yu, J.W. Ager III, J. Cryst. Growth 231 (2001) 89.

[6] Y.J. Hsu, L.S. Hong, K.F. Huang, J.E. Tsay, Thin Solid Films 419 (2002) 33.

[7] J. Sormuen, J. Toivonen, M. Sopanen, H. Lipsanen, Appl. Surf. Sci. 222 (2004) 286.

[8] Y.J. Hsu, L.S. Hong, J.C. Jiang, J.C. Chang, J. Cryst. Growth 266 (2004) 347.

[9] R.T. Lee, G.B. Stringfellow, J. Electron. Mater. 28 (8) (1999) 963.

[10] A. Mircea, A. Ougazzaden, Ph. Dasté, Y. Gao, C. Kazmierski, J.-C. Bouley, A. Carenco, J. Cryst. Growth 93 (1988) 235.

[11] V.Yu. Davydov, N.S. Averkiev, I.N. Goncharuk, D.K. Nelson, I.P. Nikitina, A.S. Polkovnikov, A.N. Smirnov, M.A. Jacobson, O.K. Semchinova, J. Appl. Phys. 82 (1997) 5097.

[12] H. Harima, J. Phys.: Condens. Matter 14 (2002) R967-R993.

[13] C.H. Chen, H. Liu, D. Streigerwald, W. Imler, C.P. Kuo, M.G. Craford, M. Ludowise, S. Lester, J. Amano, J. Electron. Mater. 25 (1996) 1004.

[14] S. Figge, T. Böttcher, S. Einfeldt, D. Hommel, J. Cryst. Growth 221 (2000) 262.

[15] A.P. Grzegorczyk, P.R. Hageman, J.L. Weyher, P.K. Larsen, J. Cryst. Growth 283 (2005) 72. 